\title{
Vitamin D status in Kancheepuram District, Tamil Nadu, India
}

\author{
John Mechenro ${ }^{1,2}$, Giriprasad Venugopal ${ }^{1,2}$, M. Buvnesh Kumar ${ }^{3,4}$, D. Balakrishnan² (D) and \\ Balakrishnan S. Ramakrishna $a^{1,2^{*}}$
}

\begin{abstract}
Background: Vitamin D has multifarious roles in maintenance of health and prevention of disease. The present study was undertaken to assess the vitamin D status of a rural adult south Indian population and to identify its associations with socioeconomic status and cultural practices.

Methods: Between June 2015 and July 2016, 424 healthy adults residing in Kattankulathur block in Tamil Nadu, India, provided venous blood samples and answered questions by personal interview. 25 -hydroxy vitamin D was estimated by ELISA.

Results: Fifty nine (13.9\%) of the 424 participants had 25OHD levels below $12 \mathrm{ng} / \mathrm{mL}$ (vitamin D deficient) and 175 (41.3\%) had 25OHD levels between 12 to $20 \mathrm{ng} / \mathrm{mL}$ (vitamin D insufficiency). In univariate analysis, demographic factors associated with vitamin D status included education, occupation, socioeconomic class, and birthplace; lifestyle factors included sun exposure time, skin surface exposed to sunlight, use of sunscreen, awareness of vitamin $D$, and consumption of fish; and hygiene related factors included source of drinking water, availability of tap water at home, and closed toilet at home. In ordinal logistic regression, the following variables were found to be independently associated with vitamin D sufficiency: Duration of daily sun exposure below $30 \mathrm{~min}$ (Odds ratio $0.31,95 \%$ confidence intervals $0.14-0.71, P=0.006$ ), sun exposure 30-60 min (OR 0.49, 95\% Cl 0.30-0.80, $P=0.004$ ), male gender (OR 2.00, $95 \% \mathrm{Cl} 1.30-3.09, P=0.002$ ), higher level of education (OR $0.80,95 \% \mathrm{Cl} 0.69-0.94, P=0.005)$, non-consumption of fatty fish (OR 0.48, 95\% Cl 0.24-0.85, $P=0.035$ ) and presence of closed toilet system at home (OR 0.59, 95\% Cl 0.37-0.93).
\end{abstract}

Conclusion: VDD and VDI are highly prevalent in this rural Indian community. The study identifies socioeconomic and behavior patterns that negatively impact vitamin D sufficiency, thus providing a basis for targeted intervention.

Keywords: Vitamin D, Deficiency, Insufficiency, Sun exposure, Epidemiology, India

\section{Background}

Vitamin D deficiency (VDD) is very prevalent in many parts of the world [1]. The major cause of VDD is lack of adequate exposure to sunlight due to various lifestyle factors and practices [1]. The amount of sunlight exposure needed to sustain adequate vitamin D levels varies with the skin colour of the individual. For white Caucasians it has been estimated that exposing the face, hands, forearms and legs to sunlight for 9 min daily during

\footnotetext{
* Correspondence: wurama@hotmail.com

${ }^{1}$ SRM Institute of Gastroenterology, Hepatobiliary Sciences \& Transplantation, SIMS Hospital, Jawaharlal Nehru Road, Vadapalani, Chennai, Tamil Nadu, India 2Department of Medical Research, SRM Medical College Hospital \& Research Centre, SRM University, Kancheepuram District, Kattankulathur, Tamil Nadu, India

Full list of author information is available at the end of the article
}

lunchtime in the UK summer would ensure vitamin D sufficiency [2], whereas an individual with brown skin would require a $25 \mathrm{~min}$ exposure under the same conditions [3]. Vitamin D can be obtained from dietary sources but few foods naturally contain vitamin $\mathrm{D}$. Foods that are fortified with vitamin D are often not consumed in quantities sufficient to meet the body's vitamin $\mathrm{D}$ requirement [1]. Overt VDD is linked to bone disease such as rickets in the very young and osteomalacia in adults. In addition, lesser degrees of VDD are associated with an increased risk of diseases as diverse as cancer, diabetes, skin disease and neuropsychiatric disease [4-7], thus making VDD a problem of public health importance.

Vitamin D3 or cholecalciferol is produced in the skin from 7-dehydrocholesterol through the action of

(c) The Author(s). 2018 Open Access This article is distributed under the terms of the Creative Commons Attribution 4.0 International License (http://creativecommons.org/licenses/by/4.0/), which permits unrestricted use, distribution, and reproduction in any medium, provided you give appropriate credit to the original author(s) and the source, provide a link to the Creative Commons license, and indicate if changes were made. The Creative Commons Public Domain Dedication waiver (http://creativecommons.org/publicdomain/zero/1.0/) applies to the data made available in this article, unless otherwise stated. 
ultraviolet (UVB) rays from the sun. Both UVB intensity and skin pigmentation contribute to the rate of D3 formation [8]. Melanin in the skin blocks UVB from reaching 7-dehydrocholesterol as do clothing and sun-screen. The intensity of UVB from sunlight varies according to season and latitude, being maximal close to the equator. Vitamin D2 or ergocalciferol can be obtained from plants and fungi, principally mushrooms, if they have been exposed to UVB. Vitamin D3 and D2 undergo 25-hydroxylation in the liver to form 25-hydroxy vitamin D (25OHD), and this further undergoes $1 \alpha$ hydroxylation in the kidney to become the active form of vitamin $\mathrm{D}$ [8]. The plasma level of 25OHD, (which is the long-lived circulating metabolite of vitamin D) is used most commonly as the marker of an individual's vitamin D status. It has been shown that the gut microbiota have the capacity to regulate 25 hydroxylation of vitamin $\mathrm{D}$ in the liver [9], thus influencing circulating 25OHD concentration.

Rickets in children is associated with circulating concentrations of $25 \mathrm{OHD}$ of less than $20 \mathrm{ng} / \mathrm{mL}(50 \mathrm{nmol} / \mathrm{L})$ [10], as is osteomalacia in adults [11]. Circulating levels of $25 \mathrm{OHD}$ of less than $20 \mathrm{ng} / \mathrm{mL}$ have been advocated as a cut-off to define VDD [12], ,but the more restrictive Institute of Medicine recommendations suggest the use of circulating $250 \mathrm{HD}$ levels less than $12 \mathrm{ng} / \mathrm{mL}$ to define VDD, and levels between 12 and $20 \mathrm{ng} / \mathrm{mL}$ to define vitamin D insufficiency (VDI) [13]. In the present study, we use the more restrictive definition of VDD.

Social, economic and cultural factors determine an individual's access to resources, including material goods, healthcare, and educational opportunities. Population health and nutritional status is influenced by socioeconomic status and other social determinants, and these are used in risk predictive modeling of disease [14, 15]. In India, the Kuppuswamy scale and its modifications are used to classify the socioeconomic status of a family using a composite score of education and occupation of the head of the family along with monthly income of the family [16].

Vitamin D status is poor in many countries, with less than $50 \%$ of people worldwide being vitamin D sufficient. Deficiency is more common in the Middle East, China, Mongolia and India [17]. It is reported that only about $20 \%$ of healthy Indians have vitamin D sufficiency $[18,19]$, and this is a matter of particular concern given that the country has adequate sunshine. This may indicate a major role for social and cultural factors in the determination of an individual's vitamin $\mathrm{D}$ status.

The present study was undertaken to assess the vitamin D status of a rural adult south Indian population and to identify its associations with socioeconomic and cultural factors.

\section{Methods}

\section{Study area and study design}

This cross-sectional study was conducted in the Kattankulathur (latitude: $12^{\circ} 81^{\prime} 10^{\prime \prime} \mathrm{N}, 80^{\circ} 03^{\prime} 05^{\prime \prime} \mathrm{E}$ ) block of Kancheepuram district in Tamil Nadu, India. The block comprises 39 villages with 133 habitations with a total population of 213,850 as enumerated in 2012-2013. Study participants were apparently healthy adult men and women living in these villages. The inclusion criteria for the study were that individuals should be healthy, aged 18 years or more, residing in the study area for at least 1 year prior to the study, and willing to provide written consent to participate in the study. Those with self-reported coronary artery disease, arthritis, or cancer were excluded. The study was undertaken over a 14 month period from June 2015 to July 2016. A modified $30 \times 7$ sampling method was used [20,21]. Assuming a community VDD prevalence of $50 \%$ (a conservative estimate derived from published data from India [19]) a sample size of 420 was calculated. The sample size calculation formula was $\mathrm{z}^{2 * *} \mathrm{p} * \mathrm{q} / \mathrm{d}^{2}$ where the standardized score for $95 \%$ confidence level $(Z)=1.96, p=0.5, q=1-p=0.5 \& d=0.5$, to estimate a VDD prevalence of $50 \%$ with a $\pm 5 \%$ error margin. Using a 30-cluster sampling, the sample size was calculated as 14 adults per cluster or a total of 420 adults. Thirty of the 133 habitations in Kattankulathur were selected, and the houses to be sampled were chosen accordingly.

\section{Data collection and sampling}

Data collection was undertaken between June to September 2015. Participants were selected in the study area as follows. The first participating household was selected using the Expanded Programme on Immunization (EPI) recommendation [20], i.e., the centre of the area corresponding to the selected habitation was reached and a direction was selected after spinning a bottle and following the direction in which the cap pointed. The first house in that direction was selected as the first household and the first eligible adult encountered in that house was recruited. Subsequent households were selected by following the EPI strategy of going to the household whose door was nearest to the current household until 14 eligible participants accrued in that habitation.

An interview schedule was created. Informed written consent was obtained from each of the participants. Each participant was interviewed directly by the first author using a predesigned form (Additional file 1). Data was collected on demographic profile and socioeconomic status (age, sex, marital status, education, income, occupation, and the following life style factors: Duration of sun exposure, body surface area exposed to sunlight, use of sunscreen while going outdoors, intake of fatty 
fish, beef, liver and milk. Participants were asked to recall the average duration spent outdoors during weekdays and the weekend in the past 1 month and this was categorized as $15-30 \mathrm{~min}, 30-60 \mathrm{~min}, 1-2 \mathrm{~h}$ and $>2 \mathrm{~h}$ per day [22]. The body surface exposed to sunlight when going outdoors was categorized as fully covered (only hands and feet exposed), wearing short sleeves (exposing hands, arms and forearms), wearing short sleeved T-shirt and shorts or dhoti (a single cloth tied around the waist and hitched up to expose the legs) or only wearing shorts or dhoti (which also exposed the torso) [22]. Data on average intake of fatty fish, beef, liver (from poultry or cattle) and milk were obtained by asking participants to recall their intake in the 2 weeks prior to interview. Data were also obtained on use of multivitamin supplements containing vitamin D, and general awareness about vitamin $\mathrm{D}$. The latter was verified by asking whether the participant had heard of vitamin $\mathrm{D}$, whether he or she had learnt anything about vitamin $\mathrm{D}$ in school, through television, or through promotional literature distributed by health organizations or in advertisements. In addition, we asked questions on birth (urban versus rural), source of drinking water for the household, use of boiled or bottled water at home, availability of tap water at home, and availability of a close toilet system at home. This latter set of questions as aimed at elucidating information related to hygiene factors that are believed to influence the composition of the gut microbiome of an individual. Data were assigned into categories for analysis. Socioeconomic status was assigned using a modified Kuppuswamy score which was calculated based on the level of education, occupation and income of the head of the household [16].

\section{Sample collection and vitamin D assay}

Venous blood samples were collected at home from consenting participants using Vacutainers and were transported to the laboratory within an hour. Samples were immediately centrifuged to separate the serum which was stored at $-20^{\circ} \mathrm{C}$. Total $25-\mathrm{OH}$ vitamin $\mathrm{D}$ was measured in duplicate by ELISA using the DIAsource 25-OH Vitamin D Total kit (Catalog No. KAP1971, DIAsource Immunoassays SA, Louvain-la Neuve, Belgium), which uses monoclonal antibodies to measure 25-OH D2 and 25-OH D3 and has been certified by the Vitamin D External Quality Assessment Scheme. The intra-assay coefficient of variation (range $2.7-7.8 \%$ ) and the inter-assay coefficient of variation (range 4.7-9.4\%) for this assay were both less $10 \%$. Appropriate controls and calibrators (provided with each kit) were used with each ELISA plate to generate standard curves. Based on the level, an individual was classified as vitamin D deficient if serum level was $<12 \mathrm{ng} / \mathrm{mL}$, vitamin D insufficient if $12-20 \mathrm{ng} / \mathrm{mL}$, and vitamin D replete or sufficient if $>20$ [13]. The vitamin $\mathrm{D}$ estimation was done at the GI Research Lab, SIMS Hospitals, Vadapalani, Chennai, by an investigator who was blinded to the participant characteristics.

\section{Statistical analysis}

Data were entered in MS-Excel and analyzed using IBM SPSS version 20. In univariate analysis, Pearson's chi-square test was used to determine association of the variables with vitamin $\mathrm{D}$ status. $P$ values $<0.05$ were considered as statistically significant. Variables that were associated with vitamin $\mathrm{D}$ status on univariate analysis with $P$ values less than 0.10 (this $P$ value was selected in order to limit the number of variables in the model) were entered into an ordinal logistic regression analysis in which vitamin D status was the dependent variable with the ordinal categories ordered as deficient, insufficient, and sufficient. The independent variables introduced into the model as factors were sun exposure time per day, SES group, gender and age group, consumption of fish and consumption of milk; educational qualification, occupation, birth place, awareness of VDD, source of drinking water, boiled drinking water, tap water available at home and closed toilet system at home were included as covariates. There were many cells with small observed and predicted counts, and the goodness-of-fit statistic showed a Pearson Chi-square of 848.087 and Deviance Chi-square of 766.370 (df 807. Since there were cells with small observed counts, the overall model fitting test showed a-2 $\log$ likelihood of 841.124 for intercept only compared to 772.151 for the final model, leading to a Chi-square of 68.973 (df 11) and a significance $<0.0001$, indicating that the model with the predictors was valid. The proportional odds assumption of ordinal logistic regression analysis was tested using the test of parallel lines. The test showed a $-2 \log$ likelihood of 752.48 for the null hypothesis model compared to 728.942 for the general model, leading to a Chi-square of 23.538 ( $d f$ 19) and a significance of 0.214 thus affirming the null hypothesis that the proportional odds were the same across response categories. Odds ratios and 95\% confidence intervals are presented for the variables that showed independent association with vitamin D status.

\section{Results \\ Demographics}

The total number of households approached for participation in the study was 1432, of which 432 individuals gave consent and were interviewed, and 424 gave blood samples for the study. Of the 424 participants, 179 (42\%) were male. The mean (SD) age was 38.2 (16.3) years for the male participants and 42.5 (13.5) years for the female participants. 


\section{Overall vitamin D status of the population}

Overall mean (SD) 25OHD levels were 20.5 (9.3) ng/mL in the participants, and were 21.8 (10.7) among males compared to 19.7 (8.0) in women. The median value was $19.2 \mathrm{ng} / \mathrm{mL}$ and the range was 7.6 to $100.8 \mathrm{ng} / \mathrm{mL}$. Of the 424 participants, 190 had vitamin 25OHD levels higher than $20 \mathrm{ng} / \mathrm{mL}$, indicating that only $44.8 \%$ of this adult population was vitamin D sufficient. One hundred and seventy five participants had vitamin $\mathrm{D}$ levels between 12 and $20 \mathrm{ng} / \mathrm{mL}$ (VDI) and 59 had levels less than $12 \mathrm{ng} / \mathrm{ml}$ (VDD).

Association of vitamin D status with demographic factors Demographic variables that were significantly associated with vitamin D status included the educational status of the individual, the occupational profile of the individual, the socioeconomic class, and birth in a rural or urban area. Gender, marital status, age, community, and religion did not show significant associations with vitamin D status (Table 1).

\section{Association of vitamin D status with lifestyle factors}

Exposure to sunlight is the major natural source of Vitamin $\mathrm{D}$, and varied from $15 \mathrm{~min}$ per day to $>120 \mathrm{~min}$ per day. Sun exposure time per day, portions of the body exposed to sunlight, usage of sunscreen, and awareness of vitamin D, were all significantly associated with vitamin $\mathrm{D}$ status in univariate analysis. Only 16 individuals $(3.8 \%$ of the surveyed population) used vitamin $\mathrm{D}$ and other vitamin supplements. Vitamin D status was not associated with usage of multivitamins containing vitamin D (Table 2).

\section{Association of vitamin D status with consumption of specific foods}

Consumption of fish was associated with vitamin D status, with vitamin D sufficiency in $27.8 \%$ of those who did not consume fish compared to $46.4 \%$ of those who ate fish (Table 3). Food habits that showed no association with vitamin $\mathrm{D}$ status included vegetarianism, consumption of liver, consumption of beef, and frequent consumption of milk.

\section{Association of vitamin D status with parameters of hygiene}

Hygiene parameters were evaluated in view of their importance as determinants of public health and the gut microbiota in low and middle income countries. Vitamin D sufficiency was significantly less in individuals who habitually used bottled water compared to those who obtained their drinking water from a well, borewell or public tap (Table 4). Interestingly, other hygiene parameters that associated with vitamin $\mathrm{D}$ status included use

Table 1 Vitamin D status in relation to social and economic categories

\begin{tabular}{|c|c|c|c|c|c|c|}
\hline \multirow[t]{2}{*}{ Variables } & \multirow[t]{2}{*}{ Groups } & \multirow[t]{2}{*}{$n$} & \multicolumn{3}{|c|}{ Plasma $250 \mathrm{OH}$ vitamin D status } & \multirow[t]{2}{*}{$P$ value } \\
\hline & & & Deficient $(<12 \mathrm{ng} / \mathrm{mL})$ & Insufficient (12-20 ng/mL) & Sufficient (> $20 \mathrm{ng} / \mathrm{mL})$ & \\
\hline \multirow[t]{2}{*}{ Gender } & Male & 179 & $21(11.7)$ & $67(37.4)$ & $91(50.8)$ & 0.0963 \\
\hline & Female & 245 & $38(15.5)$ & $108(44.1)$ & $99(40.4)$ & \\
\hline \multirow[t]{2}{*}{ Marital status } & Unmarried & 82 & $16(19.5)$ & $32(39)$ & $34(41.5)$ & 0.2635 \\
\hline & Married / Widow & 342 & 4312.6) & $143(41.8)$ & $156(45.6)$ & \\
\hline \multirow[t]{3}{*}{ SES Category } & Upper + Upper Middle & 76 & $12(15.8)$ & $38(50)$ & $26(34.2)$ & 0.0066 \\
\hline & Lower Middle & 234 & $41(17.5)$ & $90(38.5)$ & $103(44)$ & \\
\hline & Upper Lower + Lower & 114 & $6(5.3)$ & $47(41.2)$ & $61(53.5)$ & \\
\hline \multirow[t]{4}{*}{ Age group (Years) } & $18-30$ & 135 & $26(19.3)$ & $61(45.2)$ & $48(35.6)$ & 0.0942 \\
\hline & $31-45$ & 140 & $20(14.3)$ & $55(39.3)$ & $65(46.4)$ & \\
\hline & $46-60$ & 101 & $9(8.9)$ & $41(40.6)$ & $51(50.5)$ & \\
\hline & Above 60 & 48 & $4(8.3)$ & $18(37.5)$ & $26(54.2)$ & \\
\hline \multirow[t]{2}{*}{ Education } & Up to primary school & 260 & $30(11.5)$ & $87(33.5)$ & $143(55.0)$ & $<0.0001$ \\
\hline & High school and above & 164 & $29(17.7)$ & $88(53.7)$ & 47 (28.6) & \\
\hline \multirow[t]{2}{*}{ Occupation } & Non-professional & 411 & $53(12.9)$ & $172(41.8)$ & $186(45.3)$ & 0.0029 \\
\hline & Professional & 13 & $6(46.2)$ & $3(23.1)$ & $4(30.8)$ & \\
\hline \multirow[t]{2}{*}{ Birth Place } & Rural & 393 & 49 (12.5) & $164(41.7)$ & $180(45.8)$ & 0.0085 \\
\hline & Urban & 31 & $10(32.3)$ & $11(35.5)$ & $10(32.3)$ & \\
\hline \multirow[t]{3}{*}{ Religion } & Hindu & 353 & $46(13)$ & $143(40.5)$ & $164(46.5)$ & \\
\hline & Christian & 62 & $11(17.7)$ & $28(45.2)$ & $23(37.1)$ & 0.5751 \\
\hline & Muslim & 9 & $2(22.2)$ & $4(44.4)$ & $3(33.3)$ & \\
\hline
\end{tabular}


Table 2 Association of Vitamin D status with life style factors

\begin{tabular}{|c|c|c|c|c|c|c|}
\hline \multirow[t]{2}{*}{ Variables } & \multirow[t]{2}{*}{ Groups } & \multirow[t]{2}{*}{$n$} & \multicolumn{3}{|c|}{ Plasma $25 \mathrm{OH}$ vitamin D status } & \multirow{2}{*}{$\begin{array}{l}P \\
\text { value }\end{array}$} \\
\hline & & & $\begin{array}{l}\text { Deficient (<12 ng/ } \\
\mathrm{mL})\end{array}$ & $\begin{array}{l}\text { Insufficient (12-20 ng/ } \\
\mathrm{mL} \text { ) }\end{array}$ & $\begin{array}{l}\text { Sufficient (> } 20 \mathrm{ng} / \\
\mathrm{mL} \text { ) }\end{array}$ & \\
\hline \multirow[t]{4}{*}{ Sun exposure time per day } & $15-30 \min$ & 29 & $10(34.5)$ & $12(41.4)$ & $7(24.1)$ & \multirow[t]{4}{*}{0.0001} \\
\hline & $30-60 \mathrm{~min}$ & 137 & $27(19.7)$ & $68(49.6)$ & $42(30.7)$ & \\
\hline & $60-120 \mathrm{~min}$ & 84 & $9(10.7)$ & $36(42.9)$ & $39(46.4)$ & \\
\hline & $>120 \mathrm{~min}$ & 174 & $13(7.5)$ & $59(33.9)$ & $102(58.6)$ & \\
\hline \multirow[t]{2}{*}{$\begin{array}{l}\text { Body portions exposed to } \\
\text { sunlight }\end{array}$} & $\begin{array}{l}\text { Face, upper and lower limbs } \\
\text { exposed }\end{array}$ & 86 & $10(11.6)$ & $26(30.2)$ & $50(58.1)$ & \multirow[t]{2}{*}{0.0196} \\
\hline & Face and upper limbs exposed & 338 & $49(14.5)$ & $149(44.1)$ & $140(41.4)$ & \\
\hline \multirow[t]{2}{*}{ Usage of sun screen } & No & 408 & $55(13.5)$ & $164(40.2)$ & $189(46.3)$ & \multirow[t]{2}{*}{0.0066} \\
\hline & Yes & 16 & $4(25)$ & $11(68.8)$ & $1(6.3)$ & \\
\hline \multirow{2}{*}{$\begin{array}{l}\text { Usage of vitamin D } \\
\text { supplements }\end{array}$} & No & 408 & $58(14.2)$ & $170(41.7)$ & $180(44.1)$ & \multirow[t]{2}{*}{0.3218} \\
\hline & Yes & 16 & $1(6.3)$ & $5(31.3)$ & $10(62.5)$ & \\
\hline \multirow[t]{2}{*}{ Awareness of vitamin D } & No & 356 & $48(13.5)$ & $137(38.5)$ & $171(48)$ & \multirow[t]{2}{*}{0.0081} \\
\hline & Yes & 68 & $11(16.2)$ & $38(55.9)$ & $19(27.9)$ & \\
\hline
\end{tabular}

of boiled or filtered drinking water, availability of tap water at home, and availability of a closed toilet system at home (Table 4).

\section{Multivariable analysis}

Ordinal logistic regression was done using vitamin D status as the dependent variable, in which VDD, VDI, and vitamin D sufficiency were arranged in ordinal fashion. Table 5 shows the factors that were significantly associated with vitamin D status and presents the estimate and direction of their effect on vitamin D sufficiency. Gender (females less likely to be sufficient), sunlight exposure (<60 min pre day less likely to be sufficient), educational qualification (higher education less likely to be sufficient), consumption of fish (non-consumption less likely to be sufficient), and closed toilet system at home (closed toilet less likely to be sufficient). The following factors were not associated with vitamin D status: SES, occupation, age group, birth place, use of sunscreen, awareness of vitamin D deficiency, milk consumption, source of drinking water, use of boiled/filtered water, and availability of tap water at home.

\section{Discussion}

The present study, from a rural area of Tamil Nadu, indicates that only $44.8 \%$ of the population was sufficient in vitamin D. The study further identified that vitamin D status was independently associated with time to which the body was exposed to sunlight very day, the gender of the participant, the level of education of the individual, the consumption of fatty fish, and presence of a closed toilet system at home. Each of these associations is discussed at greater length.

Both VDD and VDI were more common in individuals who had studied beyond primary school. We could not find any description of a similar observation previously in Indian studies of vitamin D status. It is possible that those individuals with higher educational attainments were involved in occupations that allowed less exposure to sunlight. The lack of vitamin D fortification in foods

Table 3 Association of Vitamin D status with dietary habits. None of the foods was fortified with vitamin D

\begin{tabular}{|c|c|c|c|c|c|c|}
\hline \multirow[t]{2}{*}{ Variables } & \multirow[t]{2}{*}{ Groups } & \multirow[t]{2}{*}{$n$} & \multicolumn{3}{|c|}{ Plasma $25 \mathrm{OH}$ vitamin D status } & \multirow{2}{*}{$\begin{array}{l}P \\
\text { value }\end{array}$} \\
\hline & & & Deficient $(<12 \mathrm{ng} / \mathrm{mL})$ & Insufficient (12-20 ng/mL) & Sufficient (> 20 ng/mL) & \\
\hline \multirow[t]{2}{*}{ Consumption of fatty fish } & No & 36 & $11(30.6)$ & $15(41.7)$ & $10(27.8)$ & \multirow[t]{2}{*}{0.0056} \\
\hline & Yes & 388 & $48(12.4)$ & $160(41.2)$ & $180(46.4)$ & \\
\hline \multirow[t]{2}{*}{ Consumption of beef } & No & 249 & $36(14.5)$ & $108(43.4)$ & $105(42.2)$ & \multirow[t]{2}{*}{0.4248} \\
\hline & Yes & 175 & $23(13.1)$ & $67(38.3)$ & $85(48.6)$ & \\
\hline \multirow[t]{2}{*}{ Consumption of liver } & No & 205 & $34(16.6)$ & $87(42.4)$ & 84 (41.) & \multirow[t]{2}{*}{0.1766} \\
\hline & Yes & 219 & $25(11.4)$ & $88(40.2)$ & $106(48.4)$ & \\
\hline \multirow[t]{2}{*}{ Consumption of milk } & No & 221 & $26(11.8)$ & $102(46.2)$ & $93(42.1)$ & \multirow[t]{2}{*}{0.0835} \\
\hline & Yes & 203 & $33(16.3)$ & $73(36.0)$ & $97(47.8)$ & \\
\hline
\end{tabular}


Table 4 Association of Vitamin D status with hygiene related factors

\begin{tabular}{|c|c|c|c|c|c|c|}
\hline \multirow[t]{2}{*}{ Variables } & \multirow[t]{2}{*}{ Groups } & \multirow[t]{2}{*}{$n$} & \multicolumn{3}{|c|}{ Plasma $25 \mathrm{OH}$ vitamin D status } & \multirow{2}{*}{$\begin{array}{l}P \\
\text { value }\end{array}$} \\
\hline & & & $\begin{array}{l}\text { Deficient } \\
(<12 \mathrm{ng} / \mathrm{mL})\end{array}$ & $\begin{array}{l}\text { Insufficient } \\
(12-20 \mathrm{ng} / \mathrm{mL})\end{array}$ & $\begin{array}{l}\text { Sufficient } \\
(>20 \mathrm{ng} / \mathrm{mL})\end{array}$ & \\
\hline \multirow{4}{*}{$\begin{array}{l}\text { Source of drinking } \\
\text { water }\end{array}$} & Bore well & 33 & $3(9.1)$ & $17(51.5)$ & $13(39.4)$ & \multirow[t]{4}{*}{0.0001} \\
\hline & Well & 19 & $2(10.5)$ & $9(47.4)$ & $8(42.1)$ & \\
\hline & Public tap & 285 & $30(10.5)$ & $106(37.2)$ & $149(52.3)$ & \\
\hline & Bottled water & 87 & $24(27.6)$ & $43(49.4)$ & $20(23.0)$ & \\
\hline \multirow{2}{*}{$\begin{array}{l}\text { Boiled/filtered } \\
\text { drinking water }\end{array}$} & No & 323 & $34(10.5)$ & 129 (39.9) & $160(49.5)$ & \multirow[t]{2}{*}{0.000} \\
\hline & Yes & 101 & $25(24.8)$ & $46(45.5)$ & $30(29.7)$ & \\
\hline \multirow[t]{2}{*}{ Tap water at home } & No & 242 & $26(10.7)$ & $94(38.8)$ & $122(50.4)$ & \multirow[t]{2}{*}{0.012} \\
\hline & Yes & 182 & $33(18.1)$ & $81(44.5)$ & $68(37.4)$ & \\
\hline \multirow[t]{2}{*}{ Closed toilet system } & No & 235 & $24(10.2)$ & $83(92)$ & $128(54.5)$ & \multirow[t]{2}{*}{0.0001} \\
\hline & Yes & 189 & $35(18.5)$ & $92(48.7)$ & $62(32.8)$ & \\
\hline
\end{tabular}

Table 5 Ordinal regression analysis with vitamin D status as the dependent variable. Vitamin D status was classified as deficient, insufficient or sufficient. Odds ratios and 95\% confidence intervals, with vitamin D sufficiency as the reference status, are shown. The category shown in parenthesis against each dichotomous variable is associated with the odds ratio of being vitamin $D$ sufficient as compared to the alternative category

\begin{tabular}{|c|c|c|c|c|}
\hline & Odds & 95\% Confidenc & & Sig. \\
\hline & & Upper bound & Lower bound & \\
\hline Birth place (Urban) & 0.61 & 0.29 & 1.29 & 0.195 \\
\hline Awareness of Vitamin D (Yes) & 1.14 & 0.66 & 2.00 & 0.631 \\
\hline Source of drinking water (Bottled) & 0.86 & 0.66 & 1.12 & 0.265 \\
\hline Drinking water boiled/filtered - (Yes) & 0.67 & 0.41 & 1.09 & 0.104 \\
\hline Tap water at home (Yes) & 1.02 & 0.65 & 1.59 & 0.931 \\
\hline Closed toilet system (Yes) & 0.59 & 0.37 & 0.93 & 0.022 \\
\hline Consumption of milk (Yes) & 1.11 & 0.74 & 1.65 & 0.613 \\
\hline Educational qualification (High school and above) & 0.80 & 0.69 & 0.94 & 0.005 \\
\hline Occupation (Professional) & 1.01 & 0.91 & 1.13 & 0.802 \\
\hline Sun exposure per day $15-30$ min & 0.31 & 0.14 & 0.71 & 0.006 \\
\hline Sun exposure per day 30-60 min & 0.49 & 0.30 & 0.80 & 0.004 \\
\hline Sun exposure per day 60-120 min & 0.82 & 0.48 & 1.40 & 0.468 \\
\hline Sun exposure per day $>120 \mathrm{~min}$ & $0^{(a)}$ & & & . \\
\hline SES Upper \& Upper Middle Class & 1.10 & 0.56 & 2.15 & 0.780 \\
\hline SES Lower Middle Class & 0.71 & 0.44 & 1.15 & 0.166 \\
\hline SES Upper Lower \& Lower Class & $0^{(a)}$ & & & . \\
\hline Gender (Male) & 2.00 & 1.30 & 3.09 & 0.002 \\
\hline Age group 18-30 years & 0.76 & 0.36 & 1.58 & 0.462 \\
\hline Age group $31-45$ years & 1.03 & 0.51 & 2.09 & 0.924 \\
\hline Age group 46-60 years & 1.35 & 0.65 & 2.82 & 0.423 \\
\hline Age group $>60$ years & $0(a)$ & & & . \\
\hline Consumption of fatty fish (No) & 0.48 & 0.24 & 0.95 & 0.035 \\
\hline
\end{tabular}


consumed in this location probably contributed to this. While occupational status was associated with VDD and VDI in univariate analysis, it was not significantly associated with vitamin D status in the multivariable analysis. In Western countries, several studies have uniformly identified higher education as being associated with better vitamin D status [23-25], quite the opposite of what we observed in our study.

Exposure to sunshine is a major factor in generating vitamin D in the body and is important in maintaining sufficiency of the vitamin in the body. The time to which the body needs to be exposed to sunlight varies with skin color. Dark skin color as is common in south India requires a longer time of exposure to sunlight for generation of vitamin D. Although we did not formally assess skin pigmentation in the study population, almost all had Type 5 skin pigmentation based on the Fitzpatrick scale [26]. The melanin pigment in skin absorbs ultraviolet radiation and protects it from damage; however it also reduced the ultraviolet radiation necessary for vitamin D synthesis in the skin. Comparative studies in the United Kingdom have shown that white-skinned Caucasians required only 9 min of daily UK summer sunlight exposure of face, forearms and lower legs to meet their vitamin D needs, while those with brown skin required 25 min of daily sunlight exposure under similar conditions $[1,2]$. Our participants had brown skin probably similar to the UK cohort in the second study above. Penetration of UVB radiation through the atmosphere is greater at midday than early in the morning. In addition to skin color and time of day, the use of clothing to cover the entire body and both upper and lower limbs and the use of sun screen were other cultural practices that were associated with VDD. In the multivariable analysis, sunlight exposure time less than 60 min per day negatively impacted vitamin D sufficiency, with $15-30$ min exposure having a greater negative effect than 30-60 min exposure per day. Our study suggests that going outdoors in the sun for greater than $60 \mathrm{~min}$ per day is required for maintaining vitamin D sufficiency. A study conducted among urban men in Pune, India also suggested that more than $1 \mathrm{~h}$ of casual midday sunlight exposure was necessary to maintain vitamin D levels [27]. In the present study, exposure of face, arms and legs to sunlight was associated protectively with VDI compared to exposure of face and arms alone.

The higher prevalence of VDD in individuals drinking protected water such as bottled water or water from bore wells is an association that has not earlier been documented. This and the other variables shown in Table 4 have been used as measures of hygiene in cross sectional association studies, and hygiene is known to influence health outcomes by effects on the composition of the gut microbiota [28]. While the association between hygiene and vitamin $\mathrm{D}$ status may be due to chance it is interesting to consider that there may be a direct link between serum
25OHD levels and domestic hygiene. The vitamin D produced in the skin is inactive and undergoes its first hydroxylation (25 hydroxylation) in the liver. The gut microbiota, through fibroblast growth factor 23, regulate 25 hydroxylation of vitamin D in the liver [9]. In germ free mice, plasma 25OHD levels were low, andincreased when gut microbiota were introduced. Since we (and other investigators) used plasma 25OHD levels to define vitamin D status, it was reasonable to include variables relating to hygiene (which greatly influences the gut microbiome) in this study evaluating associations of vitamin D status.

Sufficiency of vitamin D is necessary not only for bone health but for a variety of other metabolic and immune processes including effects mediated through vitamin D receptors distributed ubiquitously in the body. In the present study we identify associations of lifestyle and cultural practices with vitamin D status. The newly identified interaction between circulating vitamin $\mathrm{D}$, vitamin $\mathrm{D}$ receptors in the gut and the gut microbiome [29] underscores the emerging importance of vitamin D in human physiology and its role in the maintenance of health. It is very likely that poor or marginal vitamin $\mathrm{D}$ nutrition is an important determinant of ill health at both population and individual level in this population.

Limitations of the present study include that we did not consider a design effect in the initial sample size calculation, and that we did not assess the gut microbiome. The latter is a complex and sometimes unrewarding exercise, but could potentially have thrown light on the relationship between hygiene parameters and serum 25OHD concentrations.

\section{Conclusion}

Vitamin D deficiency and insufficiency were highly prevalent in this adult rural south Indian community, with educational status, time of exposure to sunlight, gender, fish consumption and hygiene being factors that independently determined the vitamin D status of individuals. These findings should help in designing and targeting interventions to improve the vitamin $\mathrm{D}$ status of the individuals residing in these communities.

\section{Additional file}

Additional file 1: Interview guide / data collection form for the study. Data were collected by the first author through personal interview of each participant using this as the guide. (DOCX $29 \mathrm{~kb}$ )

\section{Abbreviations \\ 25OHD: 25 Hydroxy Vitamin D; EPI: Expanded Programme on Immunization; SES: Socio Economic Status; VDD: Vitamin D Deficiency}

\section{Acknowledgements}

We are grateful to the Community Medicine Department, SRM Medical College Hospital \& Research Centre for assistance with the sample frame and sample collection. We are grateful to Dr. S. Pugazhendi, and Dr. Kasthuri Natarajan for their assistance. 


\section{Funding}

Not applicable.

\section{Availability of data and materials}

The data set analyzed during the current study is available from the corresponding author on reasonable request.

\section{Authors' contributions}

JM contributed to concept, design, literature search, data acquisition, data analysis, statistical analysis and manuscript preparation. GPV contributed to sample processing. BK contributed to data acquisition and statistical analysis. DB contributed to concept and design. BSR contributed to concept, design, funding, statistical analysis, manuscript editing and finalization. All authors have read and approved the manuscript. BSR is the guarantor of the article.

\section{Ethics approval and consent to participate}

The study design and consent forms were approved by the institutional ethics committee of the SRM Medical College Hospital and Research Centre. Ethics clearance number: 639/IEC/2014. Informed written consent was obtained from each participant in this study.

\section{Consent for publication}

Not applicable.

\section{Competing interests}

All authors declare that they have no competing interests.

\section{Publisher's Note}

Springer Nature remains neutral with regard to jurisdictional claims in published maps and institutional affiliations.

\section{Author details}

'SRM Institute of Gastroenterology, Hepatobiliary Sciences \& Transplantation, SIMS Hospital, Jawaharlal Nehru Road, Vadapalani, Chennai, Tamil Nadu, India. 'Department of Medical Research, SRM Medical College Hospital \& Research Centre, SRM University, Kancheepuram District, Kattankulathur, Tamil Nadu, India. ${ }^{3}$ Department of Community Medicine, SRM Medical College Hospital \& Research Centre, SRM University, Kancheepuram District, Kattankulathur, Tamil Nadu, India. ${ }^{4}$ Department of Community Medicine, Chettinad Hospital \& Research Institute, Kelambakkam, Tamil Nadu, India.

Received: 16 July 2018 Accepted: 21 November 2018

Published online: 05 December 2018

\section{References}

1. Holick MF, Chen TC. Vitamin D deficiency: a worldwide problem with health consequences. Am J Clin Nutr. 2008;87:1080S-6S.

2. Webb AR, Kazantzidis A, Kift RC, Farrar MD, Wilkinson J, Rhodes LE. Meeting vitamin D requirements in white Caucasians at UK latitudes: providing a choice. Nutrients 2018;10.pii: E497.

3. Webb AR, Kazantzidis A, Kift RC, Farrar MD, Wilkinson J, Rhodes LE. Colour counts: sunlight and skin type as drivers of vitamin D deficiency at UK latitudes. Nutrients 2018;10 pii: E457.

4. Mahendra A, Karishma CBK, Sharma T, Bansal N, Bansal R, Gupta S. Vitamin D and gastrointestinal cancer. J Lab Physicians. 2018;10:1-5.

5. Khoshbakht Y, Bidaki R, Salehi-Abargouei A. Vitamin D status and attention deficit hyperactivity disorder: a systematic review and meta-analysis of observational studies. Adv Nutr. 2018;9:9-20.

6. Hu L, Zhang Y, Wang X, You L, Xu P, Cui X, Zhu L, Ji C, Guo X, Wen J. Maternal vitamin $D$ status and risk of gestational diabetes: a meta-analysis. Cell Physiol Biochem. 2018;45:291-300.

7. Umar M, Sastry KS, Al Ali F, Al-Khulaifi M, Wang E, Chouchane Al. Vitamin D and the pathophysiology of inflammatory skin diseases. Skin Pharmacol Physiol. 2018;31:74-86

8. Bikle DD. Vitamin D metabolism, mechanisms of action and clinical applications. Chem Biol. 2014:21:319-29.

9. Bora SA, Kennett MJ, Smith PB, Patterson AD, Cantorna MT. The gut microbiota regulates endocrine vitamin $D$ through fibroblast growth factor 23 . Front Immunol. 2018;9:408.

10. Munns CF, Simm PJ, Rodda CP, Garnett SP, Zacharin MR, Ward LM, Geddes J, Cherian S, Zurynski Y, Cowell CT, APSU Vitamin D Study Group. Incidence of vitamin D deficiency rickets among Australian children: an Australian Paediatric surveillance unit study. Med J Aust. 2012;196:466-8.

11. Christodoulou S, Goula T, Ververidis A, Drosos G. Vitamin D and bone disease. Biomed Res Int. 2013;2013:396541.

12. Holick MF, Binkley NC, Bischoff-Ferrari HA, Gordon CM, Hanley DA, Heaney $\mathrm{RP}$, Murad MH, Weaver CM, Society E. Evaluation, treatment, and prevention of vitamin D deficiency: an Endocrine Society clinical practice guideline. J Clin Endocrinol Metab. 2011:96:1911-30.

13. Ross AC, Manson JE, Abrams SA, Aloia JF, Brannon PM, Clinton SK, et al. The 2011 report on dietary reference intakes for calcium and vitamin $D$ from the Institute of Medicine: what clinicians need to know. J Clin Endocrinol Metab. 2010;96:53-8.

14. Vest JR, Grannis SJ, Haut DP, Halverson PK, Menachemi N. Using structured and unstructured data to identify patients' need for services that address the social determinants of health. Int J Med Inform. 2017;107:101-6.

15. Kasthurirathne SN, Vest JR, Menachemi N, Halverson PK, Grannis SJ. Assessing the capacity of social determinants of health data to augment predictive models identifying patients in need of wraparound social services. J Am Med Inform Assoc. 2018;25:47-53.

16. Bairwa M, Rajput M, Sachdeva S. Modified Kuppuswamy's socioeconomic scale: social researcher should include updated income criteria, 2012. Indian J Comm Med. 2013;38:185-6.

17. van Schoor N, Lips P. Global overview of vitamin D status. Endocrinol Metab Clin N Am. 2017:46:845-70.

18. Ritu G, Gupta A. Vitamin D deficiency in India: prevention. causalities and interventions Nutrients. 2014;6:729-75.

19. Selvarajan S, Gunaseelan V, Anandabaskar N, Xavier AS, Srinivasamurthy S, Kamalanathan SK, Sahoo JP. Systematic review on vitamin D level in apparently healthy Indian population and analysis of its associated factors. Indian J Endocrinol Metab. 2017;21:765-75.

20. World Health Organization. Training for mid-level managers. 7. The EPI coverage survey. WHONB/08.07. Accessed on 19.06.2018 at http://apps.who. int/iris/bitstream/handle/10665/70184/WHO_IVB_08.07_eng.pdf;jsessionid= 6861D91ED0356FD26B9A72479E7468B4? sequence $=7$

21. Henderson $\mathrm{RH}$, Sundaresan T. Cluster sampling to assess immunization coverage: a review of experience with a simplified sampling method. Bull World Health Organ. 1982;60:253-60.

22. Glanz K, Yaroch AL, Dancel M, Saraiya M, Crane LA, Buller DB, Manne S, O'Riordan DL, Heckman CJ, Hay J, Robinson JK. Measures of sun exposure and sun protection practices for behavioral and epidemiologic research. Arch Dermatol. 2008;144:217-22.

23. Forrest KY, Stuhldreher WL. Prevalence and correlates of vitamin D deficiency in US adults. Nutr Res. 2011:31:48-54

24. Jääskeläinen T, Knekt P, Marniemi J, Sares-Jäske L, Männistö S, Heliövaara M, Järvinen R. Vitamin D status is associated with sociodemographic factors, lifestyle and metabolic health. Eur J Nutr. 2013;52:513-25.

25. Tønnesen R, Hovind PH, Jensen LT, Schwarz P. Determinants of vitamin D status in young adults: influence of lifestyle, sociodemographic and anthropometric factors. BMC Public Health. 2016:16:385

26. Fitzpatrick TB. The validity and practicality of sun-reactive skin types I through VI. Arch Dermatol. 1988;124:869-71.

27. Patwardhan VG, Mughal ZM, Chiplonkar SA, Webb AR, Kift R, Khadilkar W, Padidela R, Khadilkar AV. Duration of casual sunlight exposure necessary for adequate vitamin D status in Indian men. Indian J Endocrinol Metab. 2018:22:249-55.

28. Bloomfield SF, Rook GA, Scott EA, Shanahan F, Stanwell-Smith R, Turner P. Time to abandon the hygiene hypothesis: new perspectives on allergic disease, the human microbiome, infectious disease prevention and the role of targeted hygiene. Perspect Public Health. 2016;136:213-24.

29. Clark A, Mach N. Role of vitamin D in the hygiene hypothesis: the interplay between vitamin D, vitamin D receptors, gut microbiota, and immune response. Front Immunol. 2016;7:627. 